Article

\title{
Three-Dimensional Printing of Continuous Flax Fiber-Reinforced Thermoplastic Composites by Five-Axis Machine
}

\author{
Haiguang Zhang ${ }^{1, *} \mathbb{D}$, Di Liu ${ }^{1}$, Tinglong Huang ${ }^{1}$, Qingxi Hu ${ }^{1, *}$ and Herfried Lammer ${ }^{2}$ \\ 1 Rapid Manufacturing Engineering Center, School of Mechatronical Engineering and Automation, \\ Shanghai University, Shanghai 200444, China; ld523257293@shu.edu.cn (D.L.); tlhuang@shu.edu.cn (T.H.) \\ 2 Kompetenzzentrum Holz GmbH, Altenberger Straße 69, 4040 Linz, Austria; h.lammer@wood-kplus.at \\ * Correspondence: haiguang_zhang@i.shu.edu.cn (H.Z.); huqingxi@shu.edu.cn (Q.H.)
}

Received: 13 March 2020; Accepted: 1 April 2020; Published: 3 April 2020

\begin{abstract}
A method for printing continuous flax fiber-reinforced plastic (CFFRP) composite parts by five-axis three-dimensional (3D) printer, based on fused filament fabrication (FFF) technology, has been developed. FFF printed parts usually need supporting structures, have a stair step effect, and unfavorable mechanical properties. In order to address these deficiencies, continuous natural fiber prepreg filaments were first manufactured, followed by curved path planning for the model for generation of the G-code, and finally printed by a five-axis 3D printer. The surface quality of printed parts was greatly improved. The tensile strength and modulus of CFFRP increased by $89 \%$ and $73 \%$, respectively, compared with polylactic acid (PLA) filaments. The flexural strength and modulus of the 3D-printed CFFRP specimens increased by $211 \%$ and $224 \%$, respectively, compared with PLA specimens. The maximal curved bending force load and stiffness of the 3D-printed CFFRP specimens increased by $39 \%$ and $115 \%$, respectively, compared with the flat slicing method. Advanced light structures, such as leaf springs, can be designed and manufactured by taking advantage of the favorable properties of these composites, which endow them with significant potential for application in the field of automobiles.
\end{abstract}

Keywords: 3D printing; fused filament fabrication; continuous fiber-reinforced; five-axis 3D printer

\section{Introduction}

Three-dimensional (3D) printing technology, also called rapid prototyping or additive manufacturing, has been rapidly developed and widely used in various fields [1]. Fused filament fabrication (FFF) is one of most widely used 3D printing technologies due to inexpensive equipment and materials, and ease of operation [2]. FFF forms a 3D geometry by slicing a model along the XY-plane and assembling the resulting individual layers along the Z-axis, with extruded thermoplastic filaments, such as acrylonitrile butadiene styrene (ABS), polylactic acid (PLA), polypropylene (PP), or polyethylene (PE) [3]. Much research has focused on the limitations of the FFF process, such as the stair step effect and inadequate mechanical strength, and put forward corresponding solutions.

In terms of process parameter optimization, Chacón et al. [4] characterized the effect of build orientation, layer thickness, and feed rate on the mechanical performance of PLA specimens. Alaimo et al. [5] studied the influence of meso-structure and chemical composition on the mechanical behavior of ABS specimens. Mohamed et al. [6] investigated the effect of the parameters on the viscoelastic response. Sood et al. [7] predicted and optimized the parameters using an artificial neural network (ANN) in conjunction with a bacterial-foraging optimization algorithm. Bayraktar et al. [8] also used ANN to analyze the impact of melt temperature, layer thickness, and raster pattern on tensile 
strength. In summary, melt temperature and rate speed have little effect on strength. The number of contours should be as large as possible, and the layer thickness should be as small as possible. In addition, $45^{\circ}$ of the raster angle and $100 \%$ infill are the best.

Regarding path planning and the printer, Huang et al. [9-11], Jin et al. [12], Zhang et al. [13], and Allen et al. [14] proposed a curved layer slicing method in contrast with the flat layer slicing method. In order to print the path by curved layer slicing, it should be combined with a multi-axis printer. The printers are now available in many advanced design types. One such design is the Delta-type, whose variant forms include three pairs of moving parallel arms that hold the print-head in place during 3D printing operation. A more popular design is the Cartesian gantry design that is usually composed of drives along the $X$ and $Y$ axes, and a moving platform along $Z$. Isa et al. [15] added two degrees of freedom to the platform on the Delta printer model. Asif et al. [16] added the A and B axes to the extruder on the Cartesian printer model.

The main limitation of FFF is its inferiority in terms of the mechanical properties of the resulting prototypes. This led to the development of various types of alternative materials in order to improve the application domain of this technology [17]. Research on fiber-reinforced thermoplastic composites can be categorized according to the type or size of reinforcements [18]. The variables commonly used in experiments with short fiber-reinforced composites are weight fraction and fiber type, such as carbon fiber and glass fiber. Tekinalp et al. [19], Ning et al. [20,21], Anwer et al. [22], Jaszkiewicz et al. [23], and Ferreira et al. [24] studied different aspects of the above. In experiments with continuous fiber-reinforced composites, Tian et al. [25-27], Yao et al. [28], Zhang et al. [29], and Hao et al. [30] studied composite behavior and printing using continuous carbon fiber-reinforced plastic (CCFRP). On this basis, Hu et al. [31] manufactured continuous carbon fiber prepreg filaments, in which the flexural strength of the final printed parts can reach as much as $610 \mathrm{MPa}$. Caminero et al. [32] printed carbon, glass, and Kevlar fibers in the middle layer of thermoplastic using two extruders. Matsuzaki et al. [33] printed carbon and natural jute fiber composites by in-nozzle impregnation. In conclusion, continuous fiber-reinforced plastic fabricated using prepreg showed superior mechanical properties.

However, many limitations persist in the CCFRP printing process due to the stiffness of carbon fiber; most machines adopt the solution of double nozzles (e.g., Markforged [34], Anisoprint [35]). In addition, the high-cost, high-energy consumption carbon fiber manufacturing process is still significant. In contrast, natural fibers have the characteristics of light density, low price, and abundant sources. If it is possible to replace carbon fibers with natural fibers in the field of light-weight manufacturing, it will be very beneficial. At the same time, in order to improve the printing quality and mechanical strength of composites, two degrees of freedom were added to the printer. Taking into consideration the factors discussed above, this paper presents a novel method to print continuous flax fiber-reinforced plastic (CFFRP).

\section{Materials and Methods}

\subsection{CFFRP Filament Manufacturing}

As shown in Figure 1, a single screw extruder and composite extrusion mold were employed for the manufacturing process. The process could be divided into four steps as follows:

Heating: the diameter of PLA-GH401 (Guanghe Co., Ltd., Shanghai, China) pellets was $0.5 \mathrm{~mm}$, added through the barrel, and the extruder was equipped with heating and heat preservation devices, so that the solid pellets were heated to a melting state and had certain fluidity. The heating band, which could be heated up to $300{ }^{\circ} \mathrm{C}$, was placed in the front part of the single screw extruder. The melt extrusion temperature of PLA was set at $190^{\circ} \mathrm{C}$.

Extruding: the single screw extruder squeezed the molten PLA resin into the composite extrusion die. The extrusion speed of the screw was from 200 to $600 \mathrm{~mm} / \mathrm{min}$. The selected extrusion speed needed to be compatible with the composite filament diameter and collecting speed. 
Compounding: the die had a vertical opening where a 3D printer nozzle was attached and the diameter of the upper hole was $1.2 \mathrm{~mm}$. Flax fibers of which the diameter was about $0.5 \mathrm{~mm}$ were introduced and coated by the molten PLA resin as shown in Figure 1c. The diameter of the CFFRP prepreg filaments could be changed by varying the 3D printer nozzle. The flax was a two-ply yarn of 68Tex. The diameter of CFFRP prepreg filaments was set to $0.8,1.0$, and $1.2 \mathrm{~mm}$ by the 3D printer nozzle.

Collecting: the dragger machine maintained constant speed and tension during the entire manufacturing process. At the same time, the composite material was mechanically collected into rolls.
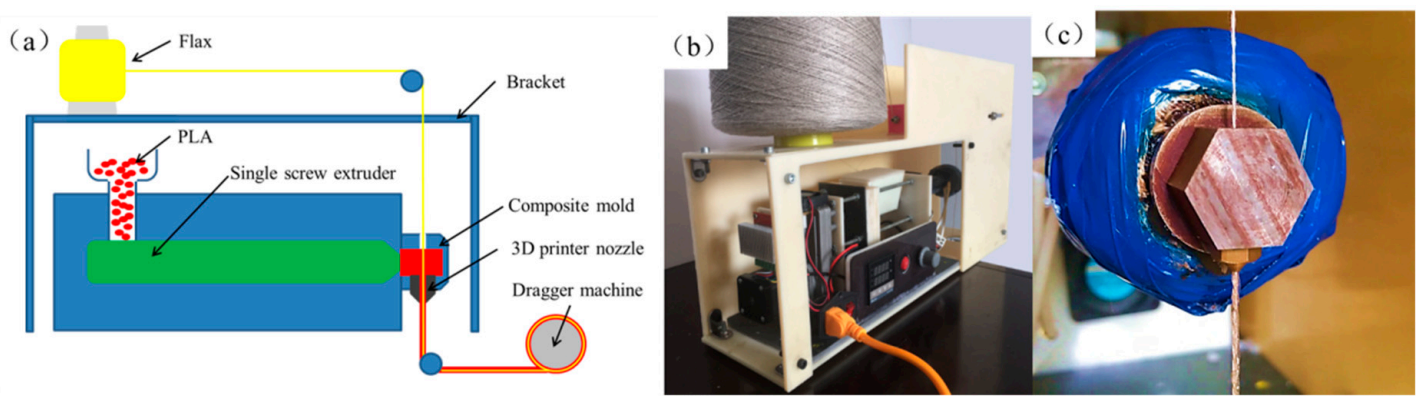

Figure 1. The production of 3D-printable continuous flax fiber-reinforced plastic (CFFRP) prepreg filaments. (a) Schematic for manufacturing CFFRP prepreg filaments. (b) Device for manufacturing CFFRP prepreg filaments. (c) Composite mold of device.

\section{2. $3 D$ Printer}

3D printed CFFRP specimens were manufactured using a five-axis 3D printer, which had an added $\mathrm{B}$-axis with an extruder that rotated around the $\mathrm{Y}$-axis and $\mathrm{C}$-axis with a platform that rotated around the Z-axis, in addition to the three ordinary axes of the Cartesian printer model. As shown in Figure 2, the overall size of the printer frame was $470 \times 450 \times 460 \mathrm{~mm}$, and the maximum size that could be printed was $100 \times 100 \times 100 \mathrm{~mm}$. The $C$-axis platform and rotating mechanisms could be removed and therefore, without the C-axis, the printing size was $190 \times 170 \times 150 \mathrm{~mm}$. When the $\mathrm{B}$-axis pointed to the negative direction of the $\mathrm{X}$-axis, it was $0^{\circ}$. However, it could be rotated from $0^{\circ}$ to $180^{\circ}$, while the C-axis could be rotated freely $\left(360^{\circ}\right)$. The shortest line of $0.2 \mathrm{~mm}$ could be printed to approximate the curve. The printer's extruder was modified, since the CFFRP could not be squeezed like pure melted PLA. The diameter of the nozzle matched the diameter of the CFFRP filaments. The printer adopted was the Atmega2560 (Airuide 3D Co., Ltd., Shenzhen, China), which used the same CPU, the Arduino MEGA, as the master control chip of the slave computer, called the RUMBA (RepRap Universal Mega Board with Allegro driver). Marlin 1.0.2 [36] was used as firmware to communicate with the host computer in order to control five-axis printing.

\subsection{Tests}

Tensile, three-point bending and curved bending tests were conducted using the microcomputer controlled electronic testing machine (WDW-1, SONGDUN Corp., Shanghai, China). Surfaces of the filaments and fracture surfaces of the tested specimens were observed with a HITACHI SU-1510 (HITACHI Ltd., Tokyo, Japan) scanning electron microscope (SEM). The geometry of the specimens was designed using computer aided design software and exported as STL files. The main dimensions of the specimens are shown in Figure 3. For tensile tests of filaments (refer to ASTM D4018 [37]), test length was $150 \mathrm{~mm}$ (Figure 3a). The tensile strength was $\sigma_{t}$ using $\sigma_{t}=\frac{F}{A}$, where $F$ is the tensile load and $A$ is the cross-sectional area of the specimen. The tensile modulus was $E_{t}$ using $E_{t}=\frac{\Delta S}{\Delta S_{t}}$, where $\Delta S$ is the stress increment and $\Delta S_{t}$ is the strain increment. 


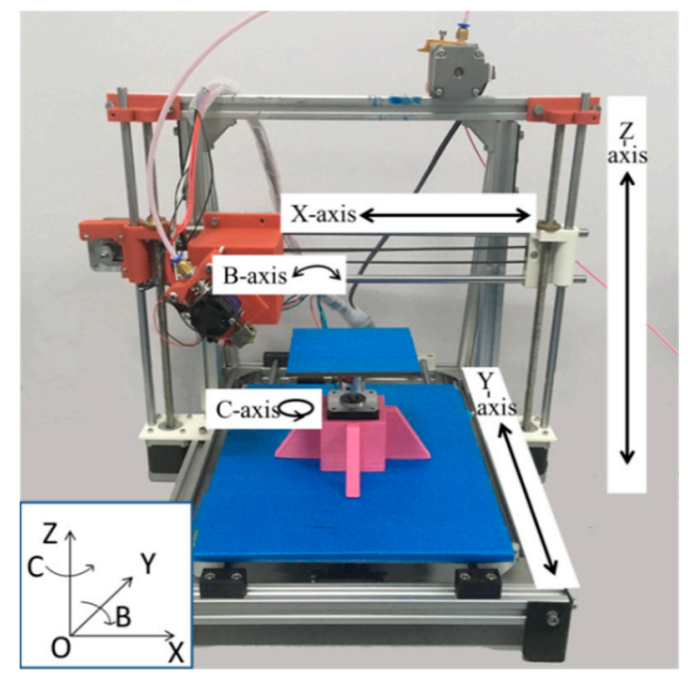

Figure 2. Five-axis 3D printer.

(a)

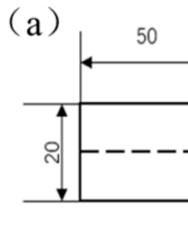

(c)

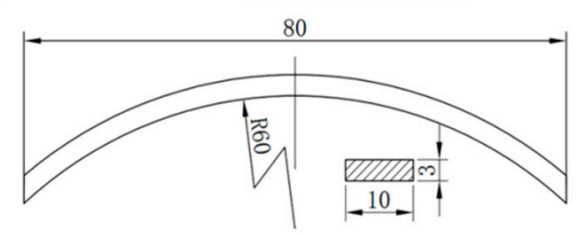

ripping device

150

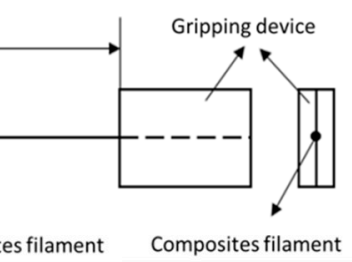

(d) (b)

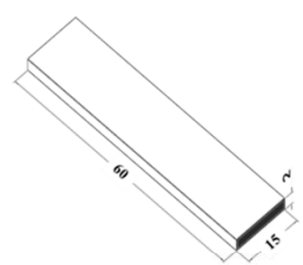

Figure 3. Standard specimens for testing. Dimensions are in $\mathrm{mm}$. (a) Specimens for CFFRP tensile test. (b) Specimens for three-point bending test. (c) Specimens for curved bending test. (d) Analysis of force of curved structure.

For three bending tests of CFFRP-printing (refer to ISO 14125:1998 [38]), the specimens were $60 \mathrm{~mm} \times 15 \mathrm{~mm} \times 2 \mathrm{~mm}$, and the support span was $40 \mathrm{~mm}$ (Figure 3b). The flexural strength was $\sigma_{f}$ using $\sigma_{f}=\frac{3 F \times L}{2 b \times h^{2}}$, where $F$ is the failure load $(\mathrm{N}), 1$ is the distance between the two supports, $b$ is the width of specimen, and $h$ is the thickness of the specimen. The $L$ was set at $40 \mathrm{~mm}$. The flexural modulus was $E_{f}$ using $E_{f}=\frac{L^{3} \times \Delta P}{4 b \times h^{3} \times \Delta S}$, where $L, b$, and $h$ have the same meaning as the variables above; $\Delta P$ is the increment of load in the initial linear part of the load and deflection curve; and $\Delta S$ is the increment of deflection corresponding to $\Delta P$ at the midpoint of $L$.

For curved bending tests, the specimens were $80 \mathrm{~mm}$ in length, $10 \mathrm{~mm}$ in width, $3 \mathrm{~mm}$ in thickness, and the radius of the curve was $60 \mathrm{~mm}$ (Figure 3c). When there was a load on the top of the specimen, analysis of force of the curved structure was calculated as shown in Figure $3 \mathrm{~d}$. It is known that the mechanical strength of fiber-reinforced polymers is highest in the direction of fiber alignment, so we tried to ensure that continuous fibers were arranged along the direction of the force gradient. The build orientation was divided into three types: upright, flat, and curved. The curved bending stiffness $k(\mathrm{~N} / \mathrm{mm})$, which refers to the ability of structures to resist elastic deformation when subjected to a force, was calculated using $k=\frac{F}{\delta}$, where $F$ is the force load (N) acting on the structure, and $\delta$ is the deformation $(\mathrm{mm})$ due to the force. Tensile tests of the CFFRP prepreg filaments and bending tests of the specimens are shown in Figure 4. 


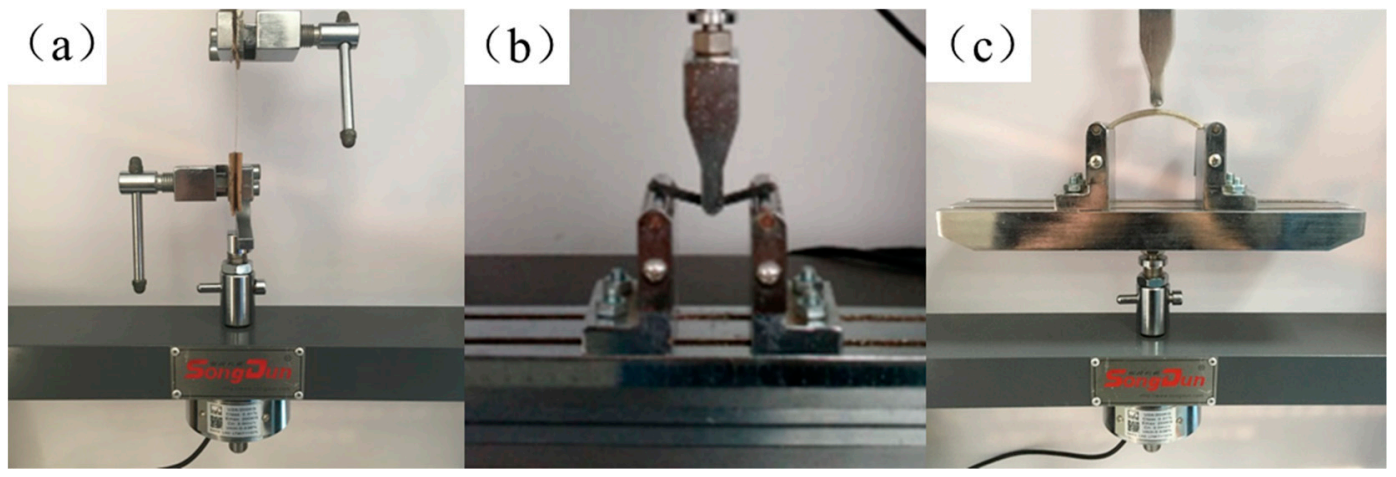

Figure 4. Specimens and tests. (a) Tensile test of CFFRP prepreg filaments. (b) Three-point bending test of continuous carbon fiber-reinforced plastic (CCFRP) specimens. (c) Curved bending test of curved CFFRP $1.0 \mathrm{~mm}$ specimens.

In curved bending test experiments, all parameters of printing except the build orientation were constant. For PLA printing, the temperature of the nozzle was $200^{\circ} \mathrm{C}$, layer thickness was the height of a single layer, chosen as $0.35 \mathrm{~mm}$, both the number of contours and number of roof and floor layers were 1 , and the fill density of specimens was $100 \%$. For upright and flat build orientation, the model was sliced using the 3D print Cura 15.04.6 [39] slicing engine, and the raster angle was $45^{\circ}$. For CFFRP printing, the thickness was $0.5 \mathrm{~mm}$ and the printing speed was $100 \mathrm{~mm} / \mathrm{min}$.

\section{Results and Discussion}

\subsection{CFFRP Filament Tests}

Tensile strength and tensile modulus test results of CFFRP filaments are shown in Figure 5. The tensile strength of PLA filaments was $47 \mathrm{MPa}$, and the tensile modulus was $1.7 \mathrm{GPa}$. When continuous flax fibers were coated by PLA, the tensile strength increased with the decrease of the CFFRP composite's diameter, which meant that the proportion of flax fiber increased. The weight fraction of flax in CFFRP is depicted in Table 1. The maximum tensile strength was $89 \mathrm{MPa}$ when the diameter of the CFFRP was $1.0 \mathrm{~mm}$, and the maximum tensile modulus was $2.9 \mathrm{GPa}$ when the diameter of the CFFRP was $0.8 \mathrm{~mm}$. SEM images of the filament surfaces are shown in Figure 6. The reason for the slight decrease in the tensile strength when the CFFRP diameter was $0.8 \mathrm{~mm}$ was that the surface-coated PLA could not be uniformly wrapped around the flax fiber due to the limitations of the machine, and there would be thinner or uncoated sections of the fiber; but a diameter of $1.0 \mathrm{~mm}$ would avoid this problem. In addition, because the composite mold had a vertical opening, during the process of composite materials forming, air would enter from the top of the opening, resulting in bubbles in the composite material and slightly increased surface roughness of the filaments. However, this did not affect the printing because the PLA outside the composite material was re-melted during the printing process.

Table 1. Weight fraction of flax in CFFRP.

\begin{tabular}{cc}
\hline Diameter of CFFRP (mm) & Weight Fraction of Flax (\%) \\
\hline 1.2 & 10.6 \\
1.0 & 20.4 \\
0.8 & 36.7 \\
\hline
\end{tabular}




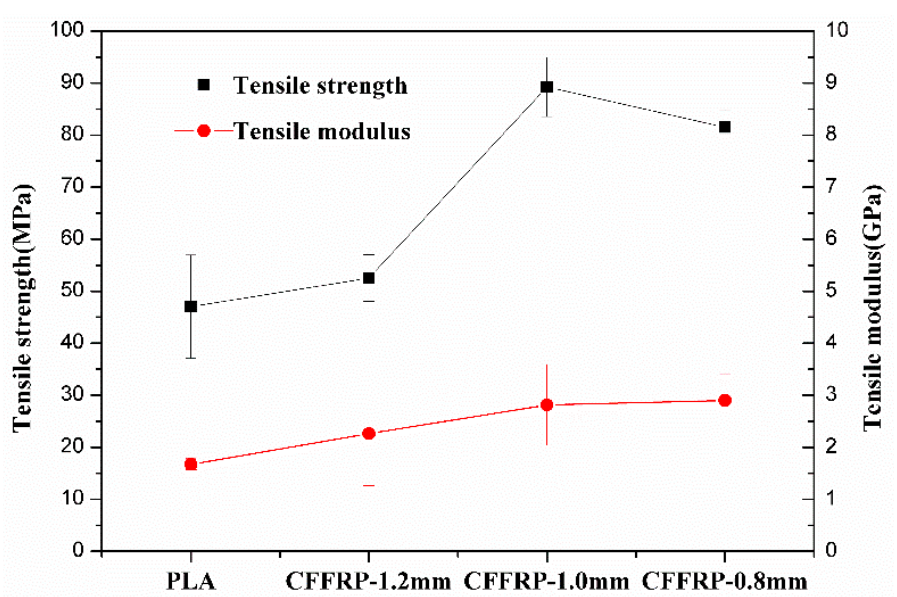

Figure 5. Tensile strength and modulus test results of CFFRP filaments.

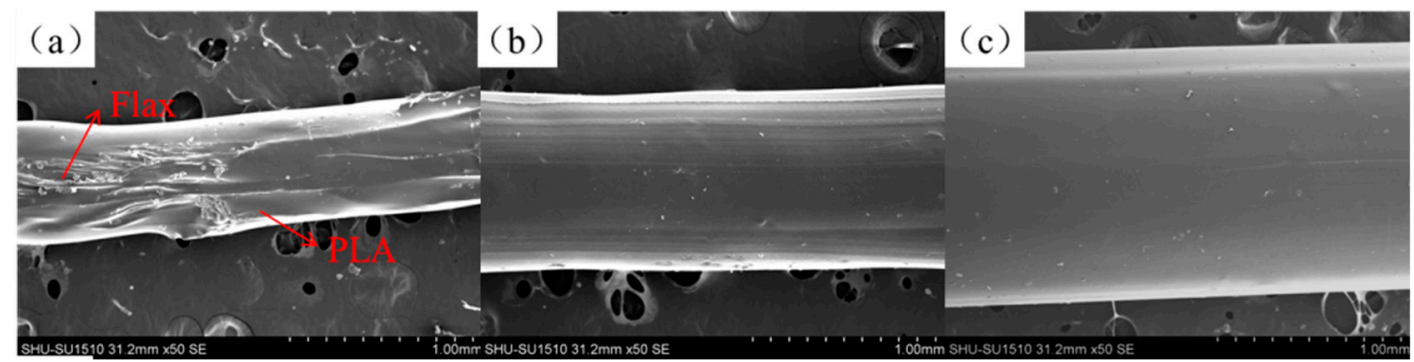

Figure 6. SEM images of the filament surfaces. (a) CFFRP $0.8 \mathrm{~mm}$. (b) CFFRP $1.0 \mathrm{~mm}$. (c) CFFRP $1.2 \mathrm{~mm}$.

\subsection{Three-Point Bending Test of CFFRP}

Figure 7 displays the three-point bending test results of three specimens printed by CCFRP, CFFRP, and PLA. Flexural strength of CFFRP-printed specimens was $132 \mathrm{MPa}, 211 \%$ higher than PLA-printed, which had flexural strength of $42 \mathrm{MPa}$, but much lower than CCFRP-printed, which had flexural strength of $372 \mathrm{MPa}$. Flexural modulus of CFFRP-printed specimens was $7.0 \mathrm{GPa}, 224 \%$ higher than PLA-printed, which had flexural modulus of $2.2 \mathrm{GPa}$. The flexural modulus of CCFRP-printed was $34.9 \mathrm{GPa}$. Although a reinforcing effect like that of CCFRP was not achieved, comprehensive consideration of the cost, environmental protection, and degradability of natural fibers suggests CFFRP is a reinforcing material with great application potential.

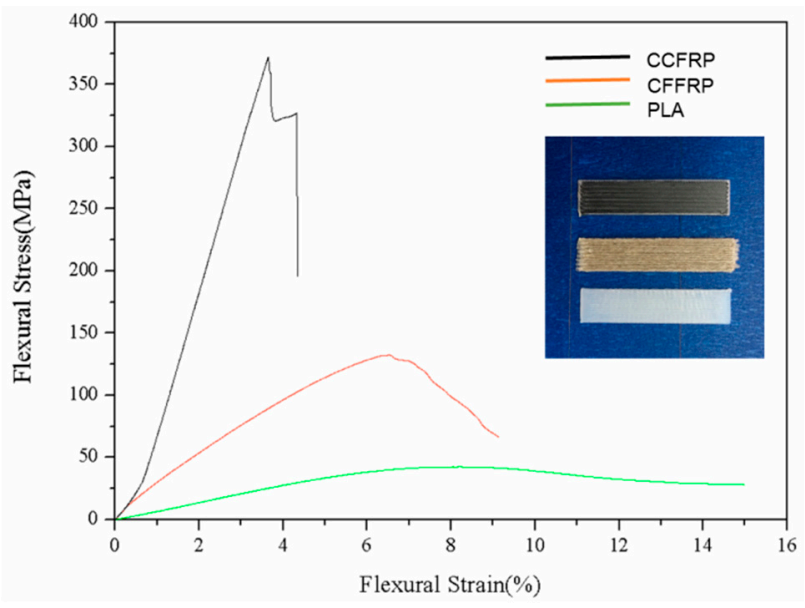

Figure 7. The three-point bending test of CCFRP, CFFRP, and PLA. 


\subsection{Build Orientation of Specimens}

Figure 8 depicts load-displacement curves of the curved bending test. As shown in Figure 9a, when the build orientation was upright, the stair step effect was obvious. The maximal curved bending load was $90 \mathrm{~N}$ and the stiffness was $14.8 \mathrm{~N} / \mathrm{mm}$. In the slicing software, the support density and distance between the support and the model entity were adjustable. However, the less the support and the larger the distance, the easier it was for the support to peel off, leading to poor support of the model and model deformation. A more serious problem was that during the process of support stripping, the surface of the model would be damaged, and the roughness would be greatly increased. In order to solve this problem, the method of printing water-soluble support materials with dual nozzles has been proposed, but it increased the cost of printing and forfeited the advantages of the FFF process. Compared with Figure 9b, when the build orientation was flat, it needed no support. However, it was not applicable to all curved surface models. Most models still needed to be supported when they were printed in the flat direction, and the surface roughness was similar to that obtained when the direction was upright. For the maximum curved bending load shown in the samples printed in PLA (non-reinforced), the value was $155 \mathrm{~N}$ because the $45^{\circ}$ intersection filling path provided a good load-bearing capacity on the stress surface in the curved bending test. Furthermore, there were large voids printed when the build orientation was upright or flat as shown in Figure 10a,b. Due to the limitation of the slicing algorithm and the shape of the extruded filaments, voids were inevitable, but reducing the voids to obtain a larger filling rate could improve the mechanical properties.

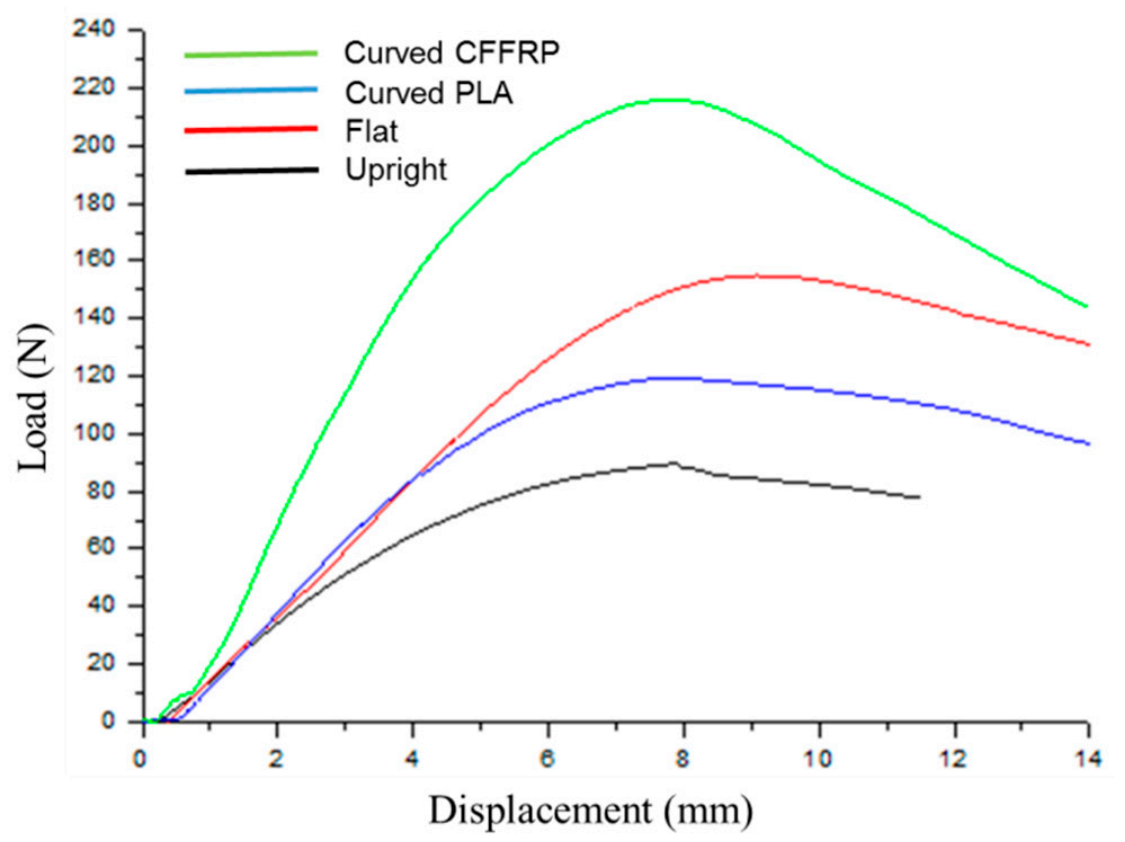

Figure 8. Load-displacement curves of curved bending test.

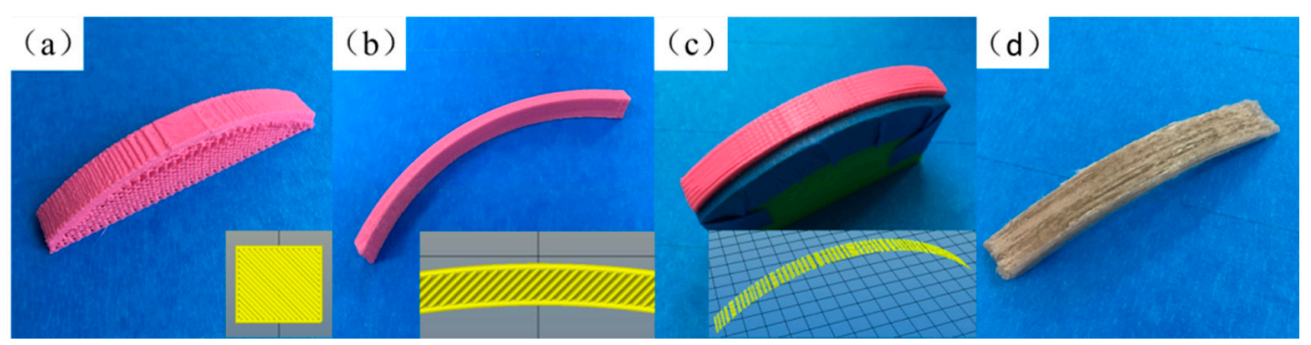

Figure 9. The build orientation of specimens. (a) Upright. (b) Flat. (c) Curved. (d) Curved CFFRP $1.0 \mathrm{~mm}$. 
Figure $9 \mathrm{c}$ displays the specimens of the curved build orientation by the five-axis machine. Although the specimens still needed support, the support did not peel off so that they were destroyed, and could be reused with the help of masking tape. The curved path eliminated the stair step effect and improved the surface quality. In the curved bending test, the maximal curved bending load was $119 \mathrm{~N}$, slightly lower than that in flat printing, which was due to the compactness of filling; that is, the void formation inside the model. The motor that controlled the rotation of the extruder was set on the X-axis rail. The additional weight of the motor caused the extruder to tilt downward slightly, which increased the instability of the nozzle. Furthermore, excessive printing speed and uneven support could cause a slight jitter of the extruder. Therefore, existing 3D printers mostly use double-rod cross-axes to install and fix, because the more stable the extruder, the higher the accuracy; the more compact the filling, the more favorable the mechanical properties. Moreover, the stiffness was the highest in PLA specimens, and the value was $23 \mathrm{~N} / \mathrm{mm}$. Because the curved path ensured the continuity of the filling of the filaments, the deformation of the continuous filaments required greater force (Figure 9c).

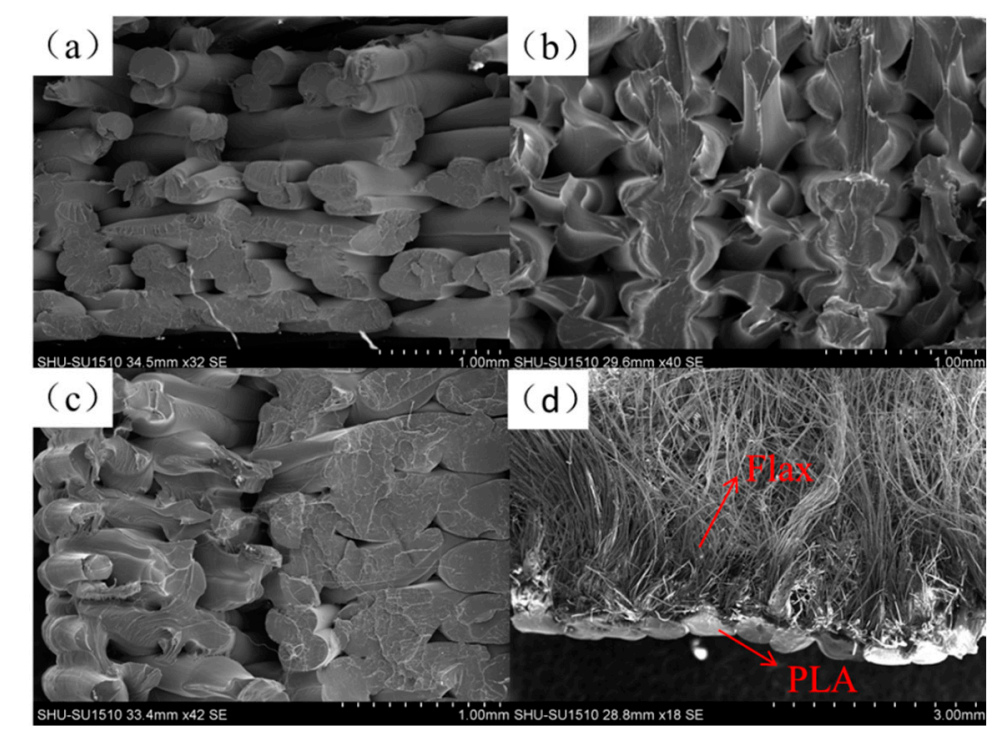

Figure 10. SEM images of the fractured surfaces of PLA specimens. (a) Upright. (b) Flat. (c) Curved. (d) Curved CFFRP.

Figures $9 \mathrm{~d}$ and $10 \mathrm{~d}$ show the details of the CFFRP specimens including fractured surfaces. Maximal curved bending load and stiffness of CFFRP composite materials were $39 \%$ and $115 \%$ higher respectively than those of flat build orientation, and $81 \%$ and $88 \%$ higher respectively than those of the same curved path printing of PLA filaments. Due to reinforcement by the flax fibers, the performance of the specimens was significantly improved.

A 3D printed leaf spring part was fabricated using CFFRP prepreg filaments and curved path planning as shown in Figure 11a. The leaf spring bears the impact of the wheel on the frame, reduces the violent vibration of the body, and maintains the stability of the vehicle, and the adaptability to different road conditions. When the leaf spring was subjected to load shock, it underwent a stretching motion; that is, extrusion tension. An advanced structure such as a shoe cap (Figure 11b) can be designed and manufactured by taking advantage of the favorable properties of this composite, which endows it with significant potential for application. The average density of specimens printed by CFFRP $1.0 \mathrm{~mm}$ composites was around $1.167 \mathrm{~g} / \mathrm{cm}^{3}$. 


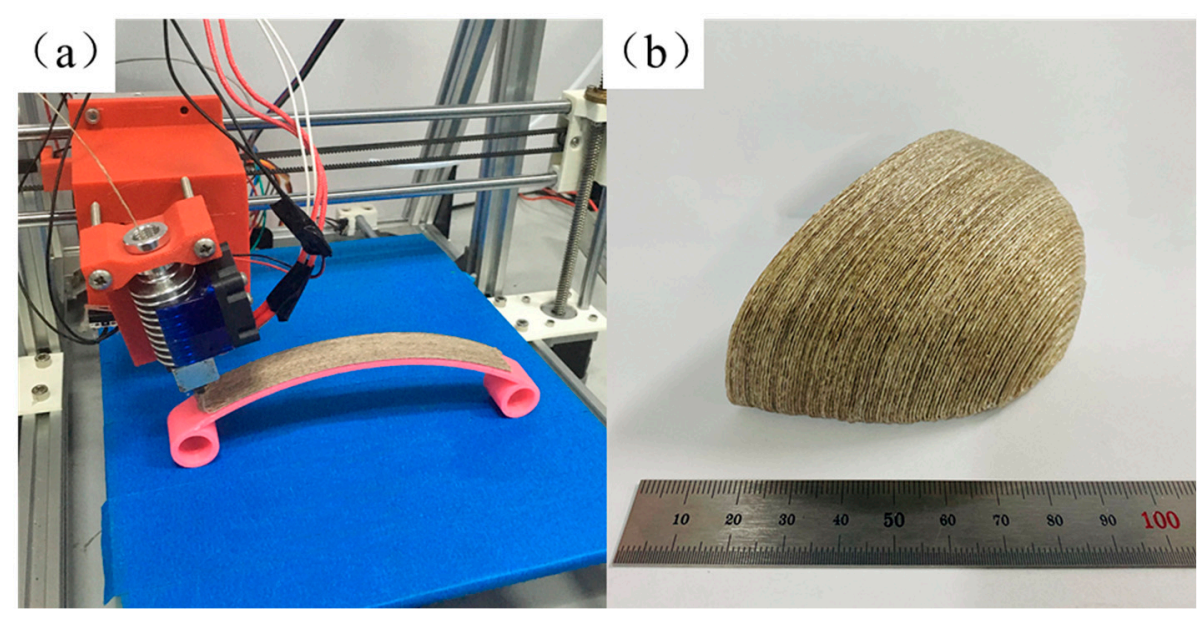

Figure 11. CFFRP component fabricated by five-axis 3D printing machine. (a) Leaf spring; (b) Shoe cap.

\section{Conclusions}

In order to improve the FFF process, prepreg filaments were manufactured as a first step. Subsequently, the angle of the extruder was calculated according to the path of the curved layer. Finally, the specimens were printed by a five-axis 3D printer which had a B-axis added to the extruder and a C-axis added to the platform of the Cartesian printer model. We studied the results of tensile tests of CFFRP and curved bending tests of printed specimens. Different ranges of two main process parameters were analyzed: the diameter of filaments and build orientation. Both achieved considerable improvement compared to parts printed with pure PLA. CFFRP filaments and curved path printing make up for the deficiencies of the FFF process. If natural fibres such as flax can be used in FFF printing of functional parts, it will have far-reaching significance in the field of composite fabrication where most demand is for low-weight and high-performance parts.

Author Contributions: H.Z. and D.L. conceived the method and designed the experiments; D.L. and T.H. performed the experiments; H.Z. and D.L. wrote the paper; Q.H. and H.Z. modified the paper; H.L. researched on the flax fiber used in the experiments; all authors revised the paper. All authors have read and agreed to the published version of the manuscript.

Funding: The authors acknowledge funding support from the National Natural Science Foundation of China (Grant No.51775324) and the Shanghai Key Laboratory of Intelligent Manufacturing and Robotics (Grant No. ZK1304). The research work was supported by the fund of Austrian-Chinese Cooperative R\&D Projects named bio-based fiber/particle reinforced thermoplastics efficiently used by 3D printing in the load path direction (FFG No.860384).

Conflicts of Interest: The authors declare no conflict of interest.

\section{References}

1. Ngo, T.D.; Kashani, A.; Imbalzano, G.; Nguyen, K.T.; Hui, D. Additive manufacturing (3D printing): A review of materials, methods, applications and challenges. Compos. Part B Eng. 2018, 143, 172-196. [CrossRef]

2. Turner, B.N.; Strong, R.; Gold, S.A. A Review of Melt Extrusion Additive Manufacturing Processes: I. Process Design and Modeling. Rapid Prototyp. J. 2014, 20, 192-204. [CrossRef]

3. Tymrak, B.; Kreiger, M.; Pearce, J. Mechanical Properties of Components Fabricated with Open-Source 3-D Printers under Realistic Environmental Conditions. Mater. Des. 2014, 58, 242-246. [CrossRef]

4. Chacón, J.; Caminero, M.; García-Plaza, E.; Núñez, P. Additive Manufacturing of PLA Structures Using Fused Deposition Modelling: Effect of Process Parameters on Mechanical Properties and Their Optimal Selection. Mater. Des. 2017, 124, 143-157. [CrossRef]

5. Alaimo, G.; Marconi, S.; Costato, L.; Auricchio, F. Influence of Meso-Structure and Chemical Composition on FDM 3D-Printed Parts. Compos. Part B Eng. 2017, 113, 371-380. [CrossRef] 
6. Mohamed, O.A.; Masood, S.H.; Bhowmik, J.L. Influence of Processing Parameters on Creep and Recovery Behavior of FDM Manufactured Part Using Definitive Screening Design and ANN. Rapid Prototyp. J. 2017, 23, 998-1010. [CrossRef]

7. Sood, A.K.; Ohdar, R.K.; Mahapatra, S.S. A Hybrid ANN-BFOA Approach for Optimization of FDM Process Parameters. In International Conference on Swarm, Evolutionary, and Memetic Computing; Springer: Berlin/Heidelberg, Germany, 2010; pp. 396-403.

8. Bayraktar, Ö.; Uzun, G.; Çakiroğlu, R.; Guldas, A. Experimental Study on the 3D-Printed Plastic Parts and Predicting the Mechanical Properties Using Artificial Neural Networks. Polym. Adv. Technol. 2016, 28, 1044-1051. [CrossRef]

9. Huang, B.; Singamneni, S.B. Curved Layer Adaptive Slicing (CLAS) for Fused Deposition Modelling. Rapid Prototyp. J. 2015, 21, 354-367. [CrossRef]

10. Singamneni, S.; Roychoudhury, A.; Diegel, O.; Huang, B. Modeling and Evaluation of Curved Layer Fused Deposition. J. Mater. Process. Tech. 2012, 212, 27-35. [CrossRef]

11. Huang, B.; Singamneni, S. A Mixed-Layer Approach Combining Both Flat and Curved Layer Slicing for Fused Deposition Modelling. P. I. Mech. Eng. B J. Eng. 2014, 229, 2238-2249. [CrossRef]

12. Jin, Y.; Du, J.; He, Y.; Fu, G. Modeling and Process Planning for Curved Layer Fused Deposition. Int. J. Adv. Manuf. Tech. 2016, 91, 273-285. [CrossRef]

13. Zhang, H.; Huang, J.; Wang, J.; Zhao, J.; Liu, D. Development of a Path Planning Algorithm for Reduced Dimension Patch Printing Conductive Pattern on Surfaces. Int. J. Adv. Manuf. Tech. 2017, 95, 1645-1654. [CrossRef]

14. Allen, R.J.; Trask, R.S. An Experimental Demonstration of Effective Curved Layer Fused Filament Fabrication Utilising a Parallel Deposition Robot. Addit. Manuf. 2015, 8, 78-87. [CrossRef]

15. Isa, M.A.; Lazoglu, I. Five-Axis Additive Manufacturing of Freeform Models through Buildup of Transition Layers. J. Manuf. Syst. 2019, 50, 69-80. [CrossRef]

16. Asif, M.; Lee, J.H.; Lin-Yip, M.J.; Chiang, S.; Levaslot, A.; Giffney, T.; Ramezani, M.; Aw, K.C. A New Photopolymer Extrusion 5-Axis 3D Printer. Addit. Manuf. 2018, 23, 355-361. [CrossRef]

17. Parandoush, P.; Lin, D. A Review on Additive Manufacturing of Polymer-Fiber Composites. Compos. Struct. 2017, 182, 36-53. [CrossRef]

18. Singh, S.; Ramakrishna, S.; Singh, R. Material Issues in Additive Manufacturing: A Review. J. Manuf. Process. 2017, 25, 185-200. [CrossRef]

19. Tekinalp, H.L.; Kunc, V.; Velez-Garcia, G.M.; Duty, C.E.; Love, L.J.; Naskar, A.K.; Blue, C.A.; Ozcan, S. Highly Oriented Carbon Fiber-Polymer Composites via Additive Manufacturing. Compos. Sci. Technol. 2014, 105, 144-150. [CrossRef]

20. Ning, F.; Cong, W.; Qiu, J.; Wei, J.; Wang, S. Additive Manufacturing of Carbon Fiber Reinforced Thermoplastic Composites Using Fused Deposition Modeling. Compos. Part B Eng. 2015, 80, 369-378. [CrossRef]

21. Ning, F.; Cong, W.; Hu, Y.; Wang, H. Additive Manufacturing of Carbon Fiber-Reinforced Plastic Composites Using Fused Deposition Modeling: Effects of Process Parameters on Tensile Properties. J. Compos. Mater. 2016, 51, 451-462. [CrossRef]

22. Anwer, M.A.; Naguib, H.E. Study on the Morphological, Dynamic Mechanical and Thermal Properties of PLA Carbon Nanofibre Composites. Compos. Part B Eng. 2016, 91, 631-639. [CrossRef]

23. Jaszkiewicz, A.; Meljon, A.; Bledzki, A.; Radwanski, M. Gaining Knowledge on the Processability of PLA-Based Short-Fibre Compounds-A Comprehensive Comparison with Their PP Counterparts. Compos. Part A 2016, 83, 140-151. [CrossRef]

24. Ferreira, R.T.L.; Amatte, I.; Dutra, T.; Bürger, D. Experimental characterization and micrography of 3D Printed PLA and PLA Reinforced with Short Carbon Fibers: An Experimental Characterization. Compos. Part B Eng. 2017, 124, 88-100. [CrossRef]

25. Tian, X.; Liu, T.; Yang, C.; Wang, Q.; Li, D. Interface and Performance of 3D Printed Continuous Carbon Fiber Reinforced PLA Composites. Compos. Part A 2016, 88, 198-205. [CrossRef]

26. Yang, C.; Tian, X.; Liu, T.; Cao, Y.; Li, D. 3D Printing for Continuous Fiber Reinforced Thermoplastic Composites: Mechanism and Performance. Rapid Prototyp. J. 2017, 23, 209-215. [CrossRef]

27. Hou, Z.; Tian, X.; Zhang, J.; Li, D. 3D Printed Continuous Fibre Reinforced Composite Corrugated Structure. Compos. Struct. 2018, 184, 1005-1010. [CrossRef] 
28. Yao, X.; Luan, C.; Zhang, D.; Lan, L.; Fu, J. Evaluation of Carbon Fiber-Embedded 3D Printed Structures for Strengthening and Structural-Health Monitoring. Mater. Des. 2017, 114, 424-432. [CrossRef]

29. Zhang, H.; Yang, D.; Sheng, Y. Performance-Driven 3D Printing of Continuous Curved Carbon Fibre Reinforced Polymer Composites: A Preliminary Numerical Study. Compos. Part B Eng. 2018, 151, 256-264. [CrossRef]

30. Hao, W.; Liu, Y.; Zhou, H.; Chen, H.; Fang, D. Preparation and Characterization of 3D Printed Continuous Carbon Fiber Reinforced Thermosetting Composites. Polym. Test. 2017, 65, 29-34. [CrossRef]

31. Hu, Q.; Duan, Y.; Zhang, H.; Liu, D.; Yan, B.; Peng, F. Manufacturing and 3D Printing of Continuous Carbon Fiber Prepreg Filament. J. Mater. Sci. 2017, 53, 1887-1898. [CrossRef]

32. Caminero, M.; Chacón, J.; García-Moreno, I.; Rodríguez, G. Impact Damage Resistance of 3D Printed Continuous Fibre Reinforced Thermoplastic Composites Using Fused Deposition Modelling. Compos. Part B Eng. 2018, 148, 93-103. [CrossRef]

33. Matsuzaki, R.; Ueda, M.; Namiki, M.; Jeong, T.-K.; Asahara, H.; Horiguchi, K.; Nakamura, T.; Todoroki, A.; Hirano, Y. Three-Dimensional Printing of Continuous-Fiber Composites by in-Nozzle Impregnation. Sci. Rep. 2016, 6, 23058. [CrossRef] [PubMed]

34. Available online: https://markforged.com/mark-two/ (accessed on 31 Mar 2020).

35. Available online: https://anisoprint.com/product-composer (accessed on 31 Mar 2020).

36. Available online: http://marlinfw.org (accessed on 31 Mar 2020).

37. Available online: https://www.astm.org/Standards/D4018.htm (accessed on 31 Mar 2020).

38. Available online: https://www.iso.org/standard/23637.html (accessed on 31 Mar 2020).

39. Available online: https://ultimaker.com/en/products/ultimaker-cura-software (accessed on 31 Mar 2020).

(C) 2020 by the authors. Licensee MDPI, Basel, Switzerland. This article is an open access article distributed under the terms and conditions of the Creative Commons Attribution (CC BY) license (http://creativecommons.org/licenses/by/4.0/). 